\title{
An Economic Evaluation of Recombinant Bovine Somatotropin Approval in Japan
}

\author{
J. Kinoshita, ${ }^{1}$ N. Suzuki, ${ }^{2}$ and H. M. Kaiser ${ }^{3}$ \\ ${ }^{1}$ Department of Food Policy Analysis, Policy Research Institute, \\ Japanese Ministry of Agriculture, 2-2-1 Nishigahara, Kita-ku, \\ Tokyo 114-0024, Japan \\ ${ }^{2}$ Department of Agricultural Economics, Kyushu University, \\ 6-10-1 Hakozaki, Higashi-ku, Fukuoka 812-8581, Japan \\ ${ }^{3}$ Department of Applied Economics and Management, \\ Cornell University, Ithaca, NY 14853-7801
}

\section{ABSTRACT}

A comprehensive econometric model was developed to evaluate potential impacts of recombinant bovine somatotropin (rbST) approval in Japan. Three novel features of the analyses include 1) investigation of impact of rbST on herd-size structure, 2) determination of economic feasibilities of rbST adoption by herd size, and 3) evaluation of policies to mitigate negative effects of rbST approval. Simulation analysis was conducted over a 10-yr projected period assuming rbST was approved in Japan in 2001. Nine hypothetical scenarios were simulated to examine sensitivity of simulation results. Simulation results indicate that rbST approval would accelerate structural change in Japan's dairy industry toward fewer, larger farms. Negative effects of rbST on farm income are projected to be more severe for smaller farms, because of higher costs, lower profitearning ability, lower milk yields, and lower adoption rates of rbST. Larger farms benefit from rbST adoption if milk demand is maintained. However, if concerns about rbST induce significant milk demand decreases, even the largest farms' income and cow numbers will decrease. Thus, Japan's dairy industry could be caught in a double downward spiral of declining milk prices and production. Assuming rbST is approved, small farms would benefit by using the technology, but they fare best if rbST is not approved. Two policies could be effective in mitigating possible farm income losses. First, lost farm income can be offset if dairy cooperatives can exercise greater market power to control fluid milk marketings. Second, because generic milk advertising has positive effects on both milk demand and farm income, increasing check-off rates to fund more advertising could ease farm income losses.

Received March 25, 2003.

Accepted September 22, 2003.

Corresponding author: H. M. Kaiser; e-mail: hmk2@cornell.edu.
(Key words: recombinant bovine somatotropin, economic evaluation, econometric model, Japan)

Abbreviation key: rbST = recombinant bovine somatotropin; see Table 2 for other symbols and abbreviations used.

\section{INTRODUCTION}

The use of biotechnologies, such as recombinant bovine somatotropin (rbST), could lower the farm costs of agricultural production. However, their use could also reduce output prices, due to increases in supply and possible decreases in demand arising from consumer concerns. Treadmill effects (Cochrane, 1959) may be more severe with biotechnologies than with conventional new technologies, for 2 reasons. First, some biotechnologies-especially those that require no significant investments-are adopted more rapidly and widely than conventional new technologies. Second, biotechnologies are more likely than conventional new technologies to arouse consumer concerns and therefore negatively affect food demand. Consequently, output price reductions resulting from the use of biotechnologies may be larger than those in conventional technology cases. Furthermore, the introduction of agricultural biotechnologies could significantly affect the structure of the agricultural market. For instance, small farms might be less likely than large farms to adopt new biotechnologies and might therefore suffer more negative effects from resulting price reductions. Hence, the introduction of such technologies might accelerate the trend toward fewer, larger farms.

In this paper, we develop a comprehensive econometric model for predicting the impacts of a new agricultural biotechnology before its approval, and we illustrate the model with a case study of rbST approval in Japan. A recombinant version of the naturally occurring bovine growth hormone that promotes lactation in milking cows was approved for commercial use in the United States in February 1994, but has not been 
approved in Japan. Japanese consumers are highly sensitive to food safety issues, as is well illustrated by the bovine spongiform encephalitis ("mad cow disease") shock to Japan's beef sector (all fluid milk in Japan is produced domestically, while about half of all dairy products consumed are currently imported without any regulations or inspections regarding rbST use). The Japanese government is also concerned that approval of rbST might lead to negative consequences not only for consumers but for dairy producers as well. Clearly, the ability to predict the potential economic implications of rbST use would be valuable to policy makers in Japan.

Our analysis includes 3 novel features that, to our knowledge, have not been explicitly integrated in past research on the economic impacts of biotechnology. First, we measure changes in milking cow numbers in individual herd-size cohorts in order to assess the impact on dairy herd structure. Second, we examine the profitability of rbST use in order to investigate how extensive rbST adoption by Japan's dairy farms could be. Last, we evaluate 2 policy alternatives for mitigating income losses due to rbST use: 1) giving dairy cooperatives greater market power to control fluid milk marketing, and 2) increasing check-offs for generic milk advertising.

\section{MODEL}

\section{Conceptual Framework}

A basic flowchart of the model is shown in Figure 1. The approval and adoption of rbST would affect milk yields and farm costs, thereby changing rbST adopters' farm income. Income changes would affect the milking cow inventory, which would alter domestic milk supply and hence milk price. Increases in milk yields with rbST and the rate of rbST adoption would likely differ among herd-size cohorts, and therefore the impacts on farm income would also differ among herd-size cohorts, which would cause a change in herd-size structure. At the same time, rbST approval might cause a decline in milk demand because of consumer concerns about rbST. A decline in milk demand would cause milk price decreases and thereby have a negative effect on farm income. In addition, rbST effects should be significantly influenced by the degree of market competitiveness and the level of generic milk advertising funded from checkoffs. In the model, milk yield increases with rbST, rbSTrelated costs, rbST adoption rates, demand decrease rates, and the degree of market competitiveness are exogenously determined, whereas farm income, milk supply, milking cow inventory, milk price, and advertising expenses are treated endogenously.

\section{Cow-Number Functions}

Most Japanese dairy farmers are primarily interested in maximizing their cash income, because unpaid family labor is the major source of dairy farm labor in Japan. Thus, we employ cash income per milking cow, instead of input/output prices, as a major explanatory variable for cow inventory decisions (this is similar to the method of Kaiser and Tauer [1989], who used economic profits as a measure of farmer's profitability). This functional equation (cow-number function) explains the number of milking cows and defines the aggregate milk supply. In our model, it is represented by 3 cow-number functions, which separately capture supply reactions of small (1 to 29 cows), medium (30 to 49 cows), and large (50+ cows) herd-size groups.

\section{Dairy Cooperatives' Market Power and Milk Prices}

Japan's milk market uses classified pricing (raw milk supply is segmented into fluid and manufacturing milk markets according to how it is marketed by processors), in order to keep the price of fluid milk higher than the price of manufacturing milk. Dairy cooperatives decide on the supply allocation between the 2 markets.

Cooperatives are required to sell all of their members' milk and to pay a blend price (weighted average price of all milk uses) to members. Farmer members make production decisions taking the blend price as given, since no member is large enough to affect the price. Hence, cooperatives are not like a monopolist that can manipulate production for price discrimination, although they can manipulate their milk allocations.

Therefore, the necessary condition to maximize cooperative milk sales is:

$$
\begin{gathered}
P S=P F+\theta D F \frac{d P F}{d D F}, \text { or } \\
P S=P F\left(1+\frac{\theta}{\eta}\right),
\end{gathered}
$$

where $P S$ is the manufacturing milk price, $P F$ is the fluid milk price, $D F$ is the quantity of fluid milk demanded, $\eta$ is the own-price elasticity of fluid milk demand, and $\theta$ is a degree-of-market-power parameter ranging from zero to one. When $\theta$ equals zero, fluid and manufacturing milk prices are equivalent, as in the case of a perfectly competitive market. When $\theta=1$, the gap in price between fluid and manufacturing milk is at its maximum, as in the case of a traditional monopolistic or perfectly collusive market. For more details on this parameter and its application in dairy models, see Suzuki et al. (1993, 1994) or Suzuki and Kaiser (1997). 


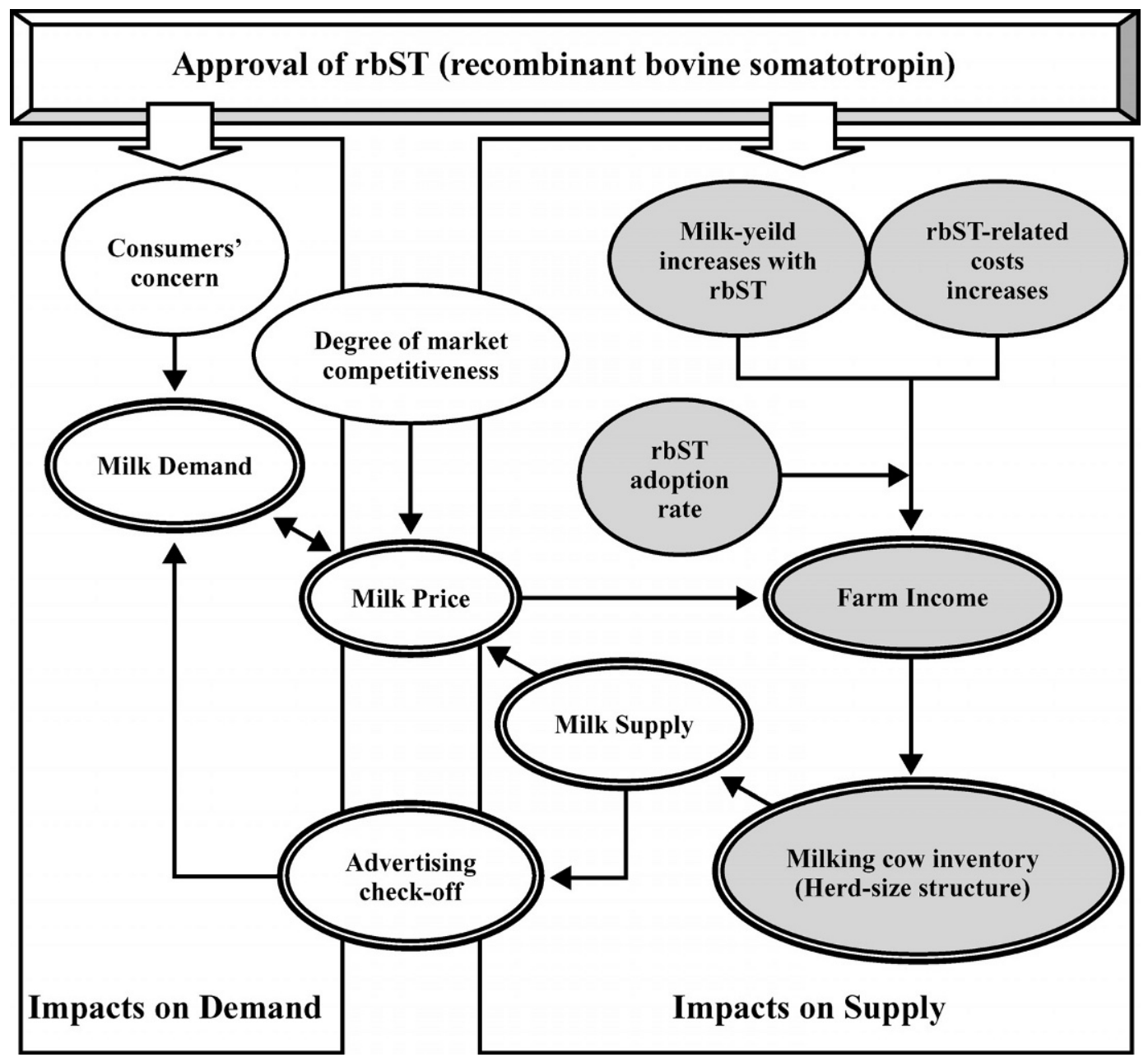

Figure 1. Basic flow chart of the rbST-model. Note: A thin circle indicates an exogenous variable/parameter, a thick circle indicates an endogenous variable, and a dotted pattern indicates a variable/parameter that has different values among herd-size groups.

The domestic manufacturing milk price charged to processors was determined by the government until the 2000 fiscal year, but has been market-determined since. Hence, it is treated as exogenous in the model until 2000 , and as endogenous thereafter. The endogenous manufacturing milk price is determined by the market equilibrium, with imports of dairy products treated exogenously.

\section{Demand Functions}

Milk demand is represented by 2 derived demand functions, one for fluid milk processors and one for manufactured dairy products processors. In the manufacturing milk demand function, both domestic and import prices are explanatory variables, because Japan's recent imports of dairy products amount to one-half of domestic consumption of dairy products on a milk- equivalent basis. We use the import price of natural cheese as a proxy for the import price.

Previous studies (e.g., Kaiser et al., 1992; Suzuki and Kaiser, 1997) have indicated that rbST could have a negative effect on milk demand. In the model, we assume the decrease in fluid milk demand to be more serious than that in manufactured dairy products, since more highly processed products containing biotechnological factors tend to have smaller negative effects.

Japan's national generic milk advertising is funded from a government subsidy and mandatory check-off money. The government subsidy is fixed. Check-offs are imposed at different per-unit rates for fluid and manufacturing milk. The manufacturing milk checkoff is collected from both farmers and dairy processors. The fluid milk check-off is collected from dairy farmers, fluid milk processors, and some of the beverage milk dealers (36.8\% of all beverage milk dealers in 2000). In 
our model, milk advertising expenditures appear in the fluid demand function as an endogenous explanatory variable. We assume that advertising effectiveness per dollar spent is the same before and after rbST approval regardless of how advertising changes in response to rbST approval.

Tauer (1994) suggested a potential for growth of an rbST-free milk market in the United States, but its actual market size is currently very small (Kuperis et al., 1999). Many reports in the United States have noted that the absence of mandatory labeling to identify rbST use could be impeding the growth of an rbST-free milk market. In Wisconsin, the voluntary use of labeling was initially pervasive, but has largely disappeared over the past $3 \mathrm{yr}$, except for organic products and specialty cheeses (Barham et al., 2004b). This is due to the technical problem that rbST residue in milk cannot be distinguished from naturally occurring bST. We assume that the situation would be the same in Japan and, consequently, do not include an rbST-free milk market in this analysis.

\section{Simulation Model}

The simulation model and its notations are shown in Tables 1 and 2. The cow-number functions (1), (2), and (3) are estimated with ordinary least squares using annual data from 1988 through 2000. Because of data limitations, only 13 observations of stratified data by herd-size are available. The demand functions (7) and (8) are estimated with ordinary least squares using annual data from 1981 through 2000.

All exogenous variables and parameters are underlined in Table 1. Although the manufacturing milk price $(P S)$ is not underlined, it is treated as exogenous until 2000 and as endogenous during the simulation period from 2001 and beyond. The manufacturing milk price was set by the government until 2000. Imports of dairy products $(I M P T)$ are treated as endogenous until 2000, as depicted in the first equation of (10). However, after $2001, I M P T$ is assumed to be exogenous (i.e., the second equation of 10) because $P S$ became endogenous.

The carcass meat price for milking cows $(P M E A T)$ is included as an explanatory variable for cow numbers, to reflect a major opportunity cost. For example, a higher carcass meat price should produce an increase in the number of cows slaughtered and therefore have a negative impact on milking cow numbers. In 1987, the standard butterfat content in milk at test was revised from 3.2 to $3.5 \%$, which had an impact on our milk quantity data. To control for this, an indicator variable equal to one for the years since 1987 and zero otherwise (DY8700) is included in both demand functions. An indicator variable (DY9000) is also included for the change in manufacturing milk consumption patterns since the 1990 s. Several existing demand analyses of Japanese milk consumption have indicated that a conspicuous (but inexplicable) change in milk products consumption patterns occurred in the 1990s (Hosono, 1999). The price of green tea (PGREEN) is used as a deflator for the fluid milk price because green tea is one of the chief substitutes for fluid milk in Japan (Kinoshita et al., 2002). The average temperature in Tokyo (TEMP) is included in the fluid demand function because Japanese consumers tend to drink more milk when the temperature increases.

Estimated own-price elasticities of manufacturing and fluid milk demand are -1.848 and -0.210 , respectively, and the expenditure elasticities are 0.564 (manufacturing) and 1.107 (fluid). Advertising expenditures, lagged one period, have a statistically significant positive impact on fluid milk demand. However, current year expenditures and those from $2 \mathrm{yr}$ prior are not statistically significant. This result is perhaps explained by the fact that national milk advertising campaigns are conducted intensively in the second half of every year. The estimated advertising elasticity of fluid milk demand is 0.069 , which is similar to the estimate of 0.058 by Suzuki et al. (1994) using monthly data for Japanese milk advertising.

\section{Model Validation}

To check for possible systematic biases associated with the separate estimation of functions, mean absolute percent errors of all endogenous variables are computed for the 1988 to 2000 period. The fully configured model is solved simultaneously by the Gauss-Seidel technique, using observational data for all exogenous variables other than the own-price elasticity of fluid milk demand $(\eta)$ and the degree-of-market-power parameter $(\theta)$. The value of $\eta$ is assumed constant at -0.210 , which is the average value during 1981 to 2000 . The annual values of $\theta$ are calibrated using equation (10). The estimated values of $\theta$ show a slight decrease during 1988 to 2000 , from 0.0700 to 0.0689 .

As shown in Table 3, all endogenous variables but dairy imports (IMPT) and the domestic manufacturing milk supply $(S M)$ have mean absolute errors less than $5 \%$. Dairy imports and $S M$ have larger errors because these variables are calculated as residuals by equations (10) and (11). Overall, the validity of the model appears to be reasonable for dynamic simulation purposes.

\section{Scenarios}

The impacts of rbST approval are simulated over a 10 -yr period beginning in 2001, under the nine hypo- 
Table 1. Simulation model. ${ }^{1}$

\begin{tabular}{|c|c|}
\hline$(1)^{2}$ & $\begin{array}{l}H_{1}=-22.232+0.905 H_{1}(-1)+0.111 I_{1}(-1) / C P I(-1) \\
\quad(-1.66) \quad(18.03) \quad(1.21)\end{array}$ \\
\hline$(2)^{2}$ & $\begin{array}{l}H_{2}=0.817 H_{2}(-1)+0.275 I_{2}(-1) / C P I(-1) \\
\quad(12.40) \\
\text { Adjusted R-squared }=0.021 \text { PMEAT/WPIF } \\
\text { (2.53) }\end{array}$ \\
\hline$(3)^{2}$ & 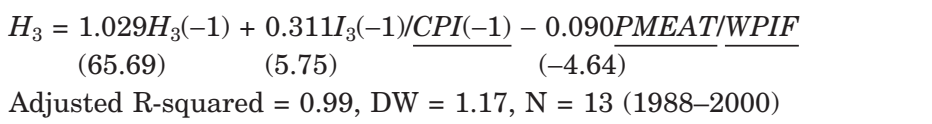 \\
\hline (4) & $I i=P \underline{Y i}(1+\underline{I R Y i} \underline{A R i})-\underline{C i}+\underline{I C i} \underline{A R i})$ \\
\hline (5) & $\underline{I C i}=\underline{I C F}+\underline{I C V} \underline{Y i} \underline{I R Y i}$ \\
\hline (6) & $S=\Sigma_{i} H i \underline{Y i}(1+\underline{I R Y i} \underline{A R i})-\underline{U}$, \\
\hline$(7)^{2}$ & $\begin{array}{l}\ln (D M / N)=7.967-1.848 \ln (P S / \underline{C P I})+0.564 \ln (\underline{E X P E N / C P I)} \\
(1.44)(-5.45) \\
(0.81) \\
-0.003 P C H E E / C P I-0.082 D Y 8700-0.121 D Y Y 9000-\ln (1+\underline{D D M}) \\
(-1.35) \\
\begin{array}{l}(-1.50) \\
\text { Adjusted R-squared }=0.93, \mathrm{DW}=1.62, \mathrm{~N}=20(1981-2000)\end{array}\end{array}$ \\
\hline$(8)^{2}$ & $\begin{array}{l}\ln (D F / \underline{N})=-5.088-0.210 \ln (P F / P G R E E N)+1.107 \ln (\underline{E X P E N / C P I}) \\
+(-2.00)(-1.29) \quad 0.014 T E M P+1.825 N R 14-0.081 \underline{D Y 8700} \\
\quad(1.51) \quad(2.02) \quad(-3.96) \\
+0.069 \ln (A D(-1) / \underline{N(-1) / C P I(-1))}-\ln (1+\underline{D D F}) \\
\quad(2.17) \quad\end{array}$ \\
\hline (9) & $A D=2 \underline{C O R M} S M(-1)+(2+\underline{C O V E R}) \underline{C O R F} D F(-1)+\underline{G O V}$, \\
\hline (10) & $\begin{array}{l}I M P T=D M-\underline{S M}-\underline{S T O K(-1)}+\underline{S O T K}+\underline{E X P T} \text { until the year } 2000 \text { or } \\
D M=\underline{I M P T}+\overline{S M}+\underline{S T O K(-1)}-\underline{\underline{S T O K}}-\underline{E X P T} \text { from the year } 2001,\end{array}$ \\
\hline (11) & $S M=S-D F$ \\
\hline (12) & $P S=P F\left(1+\frac{\theta}{\underline{\eta}}\right)$ \\
\hline (13) & $P=\frac{P F D F+(\underline{P S}+\underline{D I F F)} \underline{M Q}+P S(S M-\underline{M Q})}{S}$ \\
\hline (14) & $I=I_{1} H_{1}+I_{2} H_{2}+I_{3} H_{3}$ \\
\hline (15) & $H=H_{1}+H_{2}+H_{3}$ \\
\hline
\end{tabular}

\footnotetext{
${ }^{1}$ The underlined variable/parameter is assumed to be exogenous. $(-1)$ indicates the value of a variable in the previous period. Subscript 1, 2, and 3 indicates small (1 to 29 head), medium (30 to 49 head), and large (50+ head) herd-size group, respectively.

${ }^{2}$ Numbers in parentheses under the functions are $t$-statistics. Adjusted R-squared is the adjusted coefficient of determination. D.W. is the Durbin-Watson statistics. $\mathrm{N}$ is the number of observations.
}

thetical scenarios listed in Table 4. Scenario 0 is a norbST baseline to establish trend projections assuming no rbST approval. The remaining scenarios all assume that $\mathrm{rbST}$ was approved in 2001, but have differing values for 4 important parameters: 1) the rate of decrease in fluid and manufacturing milk demand due to rbST $(D D F$ and $D D M), 2)$ rbST adoption rates (ARi), 3 ) the degree-of-market-power parameter $(\theta)$, and (4) check-off rates for advertising of fluid and manufacturing milk (CORF and CORM).
Scenario 1 serves as an rbST baseline for the other rbST scenarios. Scenarios 2 and 3 assume that milk demand decreases slightly and significantly, respectively, while scenario 1 assumes no demand decrease. Scenario 4 assumes that all herd-size groups have the same rbST adoption rate, while scenario 1 assumes that the small herd-size group never uses rbST. Scenarios 5 and 6 assume that the milk market becomes more and less competitive, respectively, relative to 2000 , while scenario 1 assumes that it remains unchanged. Scenar- 
C Table 2. Variables and parameters of the model.

Symbolic

Definitions

Generic milk advertising expenses

RbST adoption rate (Percentage of rbST-injected cows to

total milking-cow numbers

$\begin{array}{ll}C i & \text { Cash expenses without rbST } \\ & \end{array}$

CORF Check-off money from fluid milk

CORM Check-off money from manufacturing milk

COVER

$C P I$

$D D F$

$D D M$

$D F$

$D I F F$

$D M$

DY8700

DY9000

EXPEN

EXPT Exports of dairy products in raw milk equivalents

H

$\mathrm{Hi}$

$\eta$

Ii

ICi

$I C F$

$I C V$

$M P T$

IRYi
$M Q$

$M Q$
$N$

NR14

P
PCHEE

$P F$

PGREEN

Percentage of fluid milk dealers who paid check-off money

Consumer price index for all commodities

Fluid milk demand decrease rate due to rbST

Manufacturing milk demand decrease rate due to rbST

Fluid milk quantity demanded, or domestic fluid milk supply

Government subsidy within payment quota

Indicator for the revision of standard butterfat content

Indicator for a change in milk consumption patterns

Average per capita food expenditure

Total milking-cow numbers

Milking-cow numbers

Own-price elasticity of fluid milk demand

Total farm income

Farm income ${ }^{1}$

Cash expenses associated with $\mathrm{rbST}^{1}$

rbST price

Variables costs per unit of milk-yield increases with bST

Imports of dairy products in raw milk equivalent

Increase rate of milk yield with rbST

Payment quotas for manufacturing mil

Total population in Japan

Percentage of the population under 14 years old in Japan

Blend price paid to dairy farms

CIF (cost, insurance and freight) price of imported natural

cheese with tariffs in raw milk equivalents

Fluid milk price paid by processors

Green tea price

PMEAT Carcass meat price for milking cows

$P S \quad$ Manufacturing milk price paid by processors

Degree-of-market-power parameter

$S \quad$ Domestic milk supply

SM Domestic manufacturing milk supply

STOK $\quad$ Ending stock of dairy products in raw milk equivalents

TEMP

$U$

WPIF

Average temperature in Tokyo

On-farm milk use

Wholesale price index for food

${ }^{1}$ Subscript $i$ distinguishes herd-size groups $(i=1,2,3)$

${ }^{2} \mathrm{MAFF}=$ Ministry of Agriculture, Forestry, and Fisheries

${ }^{3}$ NDPRA = National Dairy Promotion and Research Association.
Time

Unit

Sources

FY ye

total $=1$

Financial Report of the NDPRA ${ }^{3}$

(Applicable from 2001 and zero until 2000).

FY yen/cow

FY yen/kg

FY yen/kg

CY total $=1$

$1995=100$

total $=1$

total $=$
$\mathrm{kg}$

yen $/ \mathrm{kg}$

1 or 0

1 or 0

1,000 yen

$\mathrm{kg}$

FY

Feb. 1 head

Feb. 1 head

FY $\quad$ yen

FY

yen/cow

yen/cow

yen/cow

yen/

FY

total $=1$

total

FY kg

Oct. 1 person

Oct. $1 \quad$ total $=1$

FY yen/kg

CY yen $/ \mathrm{kg}$

FY yen/kg

CY yen/liter

CY yen/kg

yen/kg
$0 \leq \theta \leq 1$

$\begin{array}{ll}\text { FY } & \mathrm{kg} \\ \text { FY } & \mathrm{kg}\end{array}$

FY $\quad{ }^{\circ} \mathrm{Cg}$

FY $\quad{ }^{\circ} \mathrm{C}$

$\begin{array}{ll}\text { CY } & 1995=100 \\ \text { FY } & \mathrm{kg} / \mathrm{cow}\end{array}$

Milk Production Costs Report, $\mathrm{MAFF}^{2}$

Financial Report of the NDPRA

Financial Report of the NDPRA

Estimated from Equation (9)

Consumer Price Indices, The Bank of Japan

A

Applicable from 2001 and zero until 2000)

Food Balance Sheet, MAFF

Milk and Milk Prot, MAFr

Milk and Milk Products Statistics, MAFF

Food Balance Sheet, MAFF

(1 for the years from 1987 and zero otherwise)

( 1 for the years from 1990 and zero otherwise)

Family Income and Expenditure Survey,

Ministry of Public Management

Food Balance Sheet, MAFF

Financial Report of the NDPRA

Calculated by Equation (15)

Livestock Statistics, MAFF

Estimated from Equation (8)

Calculated by Equation (14)

Statistics of Prices and Wages in Rural Area, MAFF

(Applicable from 2001 and zero until 2000)

(Applicable from 2001 and zero until 2000)

(Applicable from 2001 and zero until 2000)

Food Balance Sheet, MAFF

(Applicable from 2001 and zero until 2000)

Milk and Milk Products Statistics, MAFF

Japan Statistical Yearbook,

Ministry of Public Management

Japan Statistical Yearbook,

Ministry of Public Management

Statistics of Prices and Wages in Rural Area, MAFF

Japan Exports and Imports, Ministry of Finance

Calculated by Equation (13)

Family Income and Expenditure Survey,

Ministry of Public Management

Meat Marketing Statistics, MAFF

Milk and Milk Products Statistics, MAFF

Calibrated by Equation (12)

Food Balance Sheet, MAFF

Food Balance Sheet, MAFF

Food Balance Sheet, MAFF

Meteorological Agency

Food Balance Sheet, MAFF

Wholesale Price Indices, The Bank of Japan

Milk Production Costs Report, MAFF 
Table 3. MAPEs ${ }^{1}$ during model validation period 1988-2000.

\begin{tabular}{lc}
\hline Endogenous variables & MAPE $(\%)$ \\
\hline Milk cow numbers & \\
$H$ & 3.26 \\
$H_{1}$ & 4.27 \\
$H_{2}$ & 2.15 \\
$H_{3}$ & 4.86 \\
Farm income & \\
$I$ & 4.83 \\
$I_{1}$ & 2.25 \\
$I_{2}$ & 2.31 \\
$I_{3}$ & 2.59 \\
Milk prices & \\
$P$ & 0.85 \\
$P F$ & 0.00 \\
Quantities & \\
$S$ & 2.58 \\
$S M$ & 7.98 \\
$D F$ & 0.96 \\
$D M$ & 3.12 \\
$I M P T$ & 13.04 \\
Advertising & \\
$A D$ & 0.98 \\
\hline
\end{tabular}

${ }^{1}$ MAPE = Mean absolute percent errors, calculated for all endogenous variables based on a 1988-2000 dynamic in-sample simulation.

ios 7 and 8 assume that the check-off rates are lower and higher, respectively, than the actual rates used in scenario 1. Values for the exogenous parameters/ variables are assumed as follows.

DDF and DDM. As we argued above, the percentage decrease in demand is larger for fluid milk than for manufacturing milk. In the United States, the actual decreases in demand for fluid and manufacturing milk caused by rbST approval were estimated to be 3.2 and 2.6\%, respectively, during 1994 to 1995 (Suzuki and Kaiser, 1997). For a longer period, Kaiser (2000) esti- mated that there was a $3.6 \%$ decrease in the total milk demand from 1994 to 2000 due to rbST approval. These estimates are smaller than most estimates from ex ante consumer surveys. It is common for actual consumer response to be smaller than anticipated by ex ante surveys (Jackson and Villinski, 2002). Judging from reactions to other genetically modified foods in Japan, it is possible that the negative response to rbST by Japanese consumers might be even more serious than that in the United States. Thus, we assume 3 sets of values, to cover a broad set of possibilities:

$$
\begin{aligned}
& D D F=0 \text { and } D D M=0, \\
& D D F=0.05 \text { and } D D M=0.025, \text { and } \\
& D D F=0.10 \text { and } D D M=0.05 .
\end{aligned}
$$

Assumption (16; baseline scenario) represents the case of no consumer concern about rbST. Assumption (17; scenario 2) represents a relatively small decrease in demand, like that in the United States. Assumption (18; scenario 3) represents a more serious decrease than has been observed in the United States.

$\boldsymbol{A R i}$. In the United States, it is difficult to determine national rbST adoption rates, because of a lack of data, but significant size biases have been reported by several surveys. For example, Monsanto (Monsanto Corporation is the only company currently producing and selling rbST in the United States) reports that about 13,000 dairy farms (13\% of the total) are using rbST and approximately one-third of milking cows in the United States received rbST in 2001 (Monsanto Corporation, 2002). This implies that the number of rbST-treated

Table 4. Differences in the key parameters' assumptions among scenarios.

\begin{tabular}{lllll}
\hline $\begin{array}{l}\text { Scenario } \\
\text { number }\end{array}$ & $\begin{array}{l}\text { Demand } \\
\text { decrease rates }\end{array}$ & $\begin{array}{l}\text { Adoption rates } \\
\text { of rbST }\end{array}$ & $\begin{array}{l}\text { Market } \\
\text { competitiveness }\end{array}$ & $\begin{array}{l}\text { Milk advertising } \\
\text { check-off money }\end{array}$ \\
\hline $\begin{array}{l}\left(\text { No-rbST baseline }^{3}\right) \\
\text { Scenario 0 }\end{array}$ & $0 \%$ & $0 \%, 0 \%, 0 \%$ & No change & Actual rates \\
$\begin{array}{l}\text { RbST scenario } \\
\text { Scenario 1 }\end{array}$ & $0 \%, 0 \%$ & $0 \%, 100^{5}, 50 \%^{5}$ & No change & Actual rates \\
Scenario 2 & $5 \%, 2.5 \%$ & $*$ & $*$ & $*$ \\
Scenario 3 & $10 \%, 5 \% 5$ & $*$ & $*$ & $*$ \\
Scenario 4 & $*$ & $50 \%, 50 \%, 50 \%{ }^{5}$ & $*$ & $*$ \\
Scenario 5 & $*$ & $*$ & More competitive & $*$ \\
Scenario 6 & $*$ & $*$ & Less competitive & $*$ \\
Scenario 7 & $*$ & $*$ & $*$ & $25 \%$ Lower rates \\
Scenario 8 & $*$ & $*$ & $*$ & $25 \%$ Higher rates \\
\hline
\end{tabular}

\footnotetext{
${ }^{1}$ The rate for fluid and manufacturing milk respectively.

${ }^{2}$ The rate for small, medium, and large herd-size group, respectively.

${ }^{3}$ Scenario 0 is used for trend projections assuming no rbST approval.

${ }^{4}$ Scenario 1 to 8 are assumed that rbST was approved in 2001 .

${ }^{5}$ This is the value in 2001 and thereafter increases one point every year from 2002.

*Means the same as Scenario 1.
} 
cows is greater for large farms than for small farms. Several surveys of Wisconsin and New York milk producers were also conducted. In Wisconsin, 3 to $10 \%$ of farms used rbST in 1994 (Barham, 1996), and 17\% used rbST in 2002 (Barham et al., 2004a). In New York, rbST users accounted for $48 \%$ of producers in 1994, and $56 \%$ in 2000 , an increase of about $1 \%$ per year during this period (Smith et al., 1995; Knoblauch and Putnam, 1997; Knoblauch et al., 1999; Knoblauch et al., 2001). In addition, a survey targeting farms with 300 or more cows showed that $88 \%$ of them were using rbST in 2000 (Karszes et al., 2001).

It may be difficult to find relevant values for our simulations from these studies, since Japan's average dairy herd-size is much smaller, viz. 37.5 cows in 2001. However, evidence suggests that dairy farms in Japan with 50 or more head are managed as effectively as large US farms. First, 50 or more head farms in Japan produce a comparable average milk yield, $8600 \mathrm{~kg}$ in 2001. Second, the adoption rate of free-stalls for these farms is $27 \%$, compared with $7 \%$ for all dairy farms in Japan. Third, a source at Monsanto reports that the management skills of Japanese dairy farms with 40 cows are comparable to those seen at 200-head farms in the United States (Suzuki, 1995). Given this evidence, we assume 2 sets of values for this study:

$$
\begin{aligned}
A R_{1}= & 0, A R_{2}=0.10+0.01 T R E N D, A R_{3}=0.50 \\
& +0.01 \text { TREND, and }
\end{aligned}
$$

$A R_{1}=A R_{2}=A R_{3}=0.50+0.01$ TREND,

where TREND is a time trend variable equal to zero in 2001 and increasing by one every year thereafter. Under assumption (19; baseline scenario), the small herd-size group does not use rbST. The adoption rates for the medium and large herd-size groups are 10 and $50 \%$, respectively, in the first year of rbST approval and are set based on evidence from the Wisconsin and New York surveys discussed above. The adoption rates for both the medium and large herd-size groups are thereafter increased by one point each year. Assumption (20; scenario 4) assumes that all groups have the same adoption rate, so that we can examine whether the small herd-size group would be better off using rbST.

$\theta$. The milk market will actually become more competitive over time, because of recent market-oriented dairy policy decisions in Japan. However, if dairy cooperatives could exercise more market power to reduce fluid milk marketing, to realize a high fluid milk price, the impacts of rbST approval might change. Therefore, 3 sets of values are assumed:

$$
\theta=0.0689,
$$

$$
\begin{aligned}
& \theta=0.0689-0.001 \text { TREND, and } \\
& \theta=0.0689+0.001 \text { TREND, }
\end{aligned}
$$

where TREND is a time trend variable equal to zero in 2001 and increasing by one every year after. Assumption (21; baseline scenario) represents constant market competitiveness at the 2000 level. Assumption (22; scenario 5) represents the more competitive market, and assumption (23; scenario 6) represents the less competitive market.

CORF and CORM. The check-off rates for fluid and manufacturing milk were 0.24 and 0.10 yen $/ \mathrm{kg}$ until 2000 , but were lowered by $25 \%$ to 0.18 and 0.075 yen/ $\mathrm{kg}$ in 2001 to compensate farmers for the recent stagnant milk price in Japan. What would happen if checkoff rates were reduced again? This question is important because further cutbacks in check-off rates might be considered as a makeshift measure to ease possible farm income losses after rbST approval. To evaluate the effect of alternative check-off rates, 3 sets of values are assumed:

$$
\begin{aligned}
& C O R F=0.18 \text { and } C O R M=0.075, \\
& C O R F=0.12 \text { and } C O R M=0.05, \\
& C O R F=0.24 \text { and } C O R M=0.10 .
\end{aligned}
$$

Assumption (24; baseline scenario) represents the actual rates since 2001, which are $25 \%$ lower than the previous levels until 2000. Assumption (25; scenario 7) represents rates $50 \%$ lower than the previous levels, and assumption (26; scenario 8) represents the rates that existed prior to 2001.

$\boldsymbol{I C F}$. The price of POSILAC, the only brand of rbST commercially available in the United States, is about $\$ 112.20$ per cow per year (Hartnell, 1995). Using the exchange rate conversion of 120 yen/dollar, we assume that the rbST price is 13,464 yen per cow per year.

$\boldsymbol{I C V}$. The increase in variable cost per unit of milk yield with rbST is assumed to correspond to additional feed cost. The other variable costs-for example, labor, mastitis treatment, and conveyance of milk-are not included in our simulations because they are small or not clearly defined (Butler, 1999; McBride et al., 2004). Using the same exchange rate conversion of 120 yen/ dollar and relying again on Hartnell (1995), we assume that the additional feed cost per unit of milk yield increase is 26.5 yen.

IRYi. It is reasonable to assume that the larger herdsize groups will achieve the highest rate of increase in milk yield with rbST because the effectiveness of rbST is affected by farmers' management skills, which are 
positively correlated with herd size. Studies in the United States have shown wide-ranging conjectures about how much milk yields could increase with rbST. Marion and Wills (1990) assumed 9.0, 12.0, and 15\%; Butler (1999) used 8 pounds/cow per day; Monsanto Corporation (2002) used 8 to 12 pounds/cow per day; Barham et al. (2004b) used 10\%; and Office of Management and Budget (1994) regarded $12 \%$ as representative. We assume the following average responses by herd-size, based on Marion and Wills (1990):

$$
I R Y 1=0.09, I R Y 2=0.12, \text { and } I R Y 3=0.15 .
$$

All exogenous variables, except total population in Japan $(N)$ and the percentage of the population under $14 \mathrm{yr}$ of age (NR14), are assumed to remain unchanged at 2000 levels. Since milk yields in Japan have been stagnant recently, we did not assume any long-term trend in milk-yield increases due to other (non-rbST) factors. For future values of $N$ and NR14, the annual population projections by the Japanese Ministry of Public Management are used.

\section{RESULTS}

Our interpretation of the simulation results focuses on the year 2010 , because this represents an adequate interval for adjustment to a long-run equilibrium following rbST approval. Estimates of all endogenous variables are listed in Table 5 as indices relative to scenario 0 simulation results.

The indices of scenario 1 indicate that while the domestic milk supply $(S)$ increases by $5.2 \%$ relative to scenario 0 , total milking-cow numbers $(H)$ decrease by $1.6 \%$. The decrease in cow numbers is due to a $3.8 \%$ decrease in the blend price $(P)$ associated with higher milk production. The net impact on revenue is a 3.3\% decline in total farm income $(I)$. Only the large herdsize group benefits in this scenario, with its income $\left(I_{3}\right)$ increasing by $6.2 \%$. With the higher income, this group experiences a $3.5 \%$ increase in cow numbers $\left(H_{3}\right)$. Accordingly, its share of cows $\left(H_{3} / H\right)$ increases from 65 to $69 \%$, which suggests that rbST approval would accelerate the structural change toward larger farms.

We examine below the indices of the remaining scenarios' simulation results in terms of their relation to scenario 1 indices.

By comparing scenarios 2 and 3 to scenario 1 , we can see how the impact of rbST approval changes with decreases in milk demand. Not surprisingly, these comparisons indicate that the more significant the decrease in milk demand, the more severe the negative impacts of rbST approval. For example, under the mild demand reduction scenario (scenario 2 ), total farm income de- creases by $8.3 \%$, compared with a $3.3 \%$ decrease in income under scenario 1 . This result is similar to what Stefanides and Tauer (1999) observed in the United States. Under the more significant demand reduction scenario (scenario 3), total farm income decreases more drastically by $12.3 \%$. In this case, domestic milk supply decreases by $3.6 \%$, but the blend price decreases by 4.3\%. This milk supply decrease induces a decrease in generic milk advertising expenditures $(A D)$, and thereby results in further decreases in both demand and price. This result suggests that if there are significant milk demand decreases after rbST approval, the dairy industry would be caught in a double downward spiral of declining milk prices and production. Note that the large herd-size group's cow number index is less than 100 in both scenarios 2 and 3 , though its farm income indices are over 100. This seemingly inconsistent result can be explained if we take into consideration a series of results throughout the simulation period that are not shown in Table 5. Just after rbST approval, the large herd-size group experiences a swift decline in cow numbers due to a significant decline in milk price and farm income. However, the income level for this group eventually increases after $10 \mathrm{yr}$ in the dynamic adjustment of price and production, as total domestic milk supply shrinks because of the swift decline in total cow numbers and milk price thereby gradually recovers.

The impact of rbST adoption on the welfare of the small herd-size group can be assessed by comparing scenarios 1 and 4 . Scenario 1 , which assumes that the small herd-size group never uses rbST, indicates that this group suffers a serious decline in income (12.8\%). On the other hand, scenario 4 indicates that if this group adopts rbST use at the same rate as the other groups (i.e., 50\%), the income loss is partially mitigated. Therefore, if rbST is approved, small farms are better off if they use it. However, they are best off when rbST is not approved.

A comparison of scenarios 5 and 6 with scenario 1 illustrates how the simulation results change with varying degrees of market competitiveness. As the milk market becomes more competitive (scenario 5), total farm income declines by $9.5 \%$. This consequence is significantly worse than the result in scenario 1 . On the other hand, as the milk market becomes less competitive (scenario 6), total farm income actually increases by $3.6 \%$. This suggests that farmers' income losses attributed to rbST approval could be offset if dairy cooperatives could exercise more market power to reduce supply to fluid milk markets. With recent moves by the Japanese government toward deregulation, it would appear that the more competitive scenario 5 is the most likely of the 3 market competitiveness scenarios. 


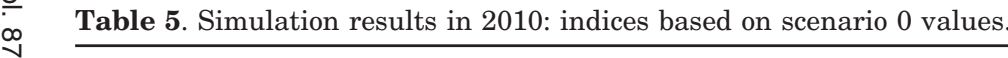

\begin{tabular}{|c|c|c|c|c|c|c|c|c|c|}
\hline \multirow[b]{2}{*}{ Endogenous variables } & \multicolumn{9}{|c|}{ Estimates in 2010} \\
\hline & Scenario 0 & Scenario 1 & Scenario 2 & Scenario 3 & Scenario 4 & Scenario 5 & Scenario 6 & Scenario 7 & Scenario 8 \\
\hline \multicolumn{10}{|l|}{ Milking cow numbers } \\
\hline $\begin{array}{l}\text { Small herd-size group } \\
(\text { Small/total })^{1}\end{array}$ & $\begin{array}{l}100.0 \\
(0.08)\end{array}$ & $\begin{array}{l}79.5 \\
(0.06)\end{array}$ & $\begin{array}{l}73.9 \\
(0.06)\end{array}$ & $\begin{array}{l}68.8 \\
(0.06)\end{array}$ & $\begin{array}{l}86.9 \\
(0.07)\end{array}$ & $\begin{array}{l}75.0 \\
(0.06)\end{array}$ & $\begin{array}{l}84.2 \\
(0.07)\end{array}$ & $\begin{array}{l}78.1 \\
(0.06)\end{array}$ & $\begin{array}{l}80.6 \\
(0.06)\end{array}$ \\
\hline Medium & 100.0 & 91.3 & 88.7 & 86.3 & 96.5 & 88.4 & 94.2 & 90.6 & 91.8 \\
\hline$(\text { Medium/total })^{1}$ & $(0.27)$ & $(0.25)$ & $(0.25)$ & $(0.25)$ & $(0.26)$ & $(0.25)$ & $(0.25)$ & $(0.25)$ & $(0.25)$ \\
\hline Large & 100.0 & 103.5 & 98.8 & 94.4 & 99.6 & 101.0 & 106.3 & 102.5 & 104.4 \\
\hline$(\text { large/total })^{1}$ & $(0.65)$ & $(0.69)$ & $(0.69)$ & $(0.68)$ & $(0.67)$ & $(0.69)$ & $(0.69)$ & $(0.69)$ & $(0.69)$ \\
\hline Total & 100.0 & 98.4 & 94.1 & 90.2 & 97.8 & 95.6 & 101.3 & 97.4 & 99.2 \\
\hline \multicolumn{10}{|l|}{ Average farm income per cow ${ }^{2}$} \\
\hline Small herd-size group & 100.0 & 87.2 & 86.5 & 85.8 & 92.9 & 84.0 & 90.7 & 87.0 & 87.4 \\
\hline Medium & 100.0 & 91.1 & 90.3 & 89.6 & 96.8 & 87.8 & 94.6 & 90.9 & 91.2 \\
\hline Large & 100.0 & 102.6 & 101.7 & 100.9 & 100.6 & 98.7 & 106.8 & 102.3 & 102.8 \\
\hline Total average & 100.0 & 98.3 & 97.5 & 96.7 & 98.9 & 94.7 & 102.3 & 98.1 & 98.5 \\
\hline \multicolumn{10}{|l|}{ Total farm income } \\
\hline Small herd-size group & 100.0 & 69.3 & 63.9 & 59.1 & 80.7 & 63.0 & 76.4 & 68.0 & 70.5 \\
\hline Medium & 100.0 & 83.1 & 80.1 & 77.4 & 93.4 & 77.7 & 89.1 & 82.3 & 83.8 \\
\hline Large & 100.0 & 106.2 & 100.5 & 95.2 & 100.2 & 99.7 & 113.5 & 104.9 & 107.3 \\
\hline Total & 100.0 & 96.7 & 91.7 & 87.3 & 96.7 & 90.5 & 103.6 & 95.5 & 97.7 \\
\hline \multicolumn{10}{|l|}{ Milk quantity } \\
\hline Domestic milk supply & 100.0 & 105.2 & 100.6 & 96.4 & 105.9 & 102.2 & 108.3 & 104.1 & 106.0 \\
\hline Domestic manufacturing supply & 100.0 & 111.2 & 107.1 & 103.2 & 112.8 & 103.0 & 119.9 & 111.0 & 111.3 \\
\hline Quantity of fluid milk demanded & 100.0 & 100.7 & 95.8 & 91.3 & 100.8 & 101.6 & 99.8 & 99.0 & 102.2 \\
\hline \multicolumn{10}{|l|}{ Milk price } \\
\hline Fluid milk price & 100.0 & 97.1 & 96.8 & 96.6 & 96.7 & 93.2 & 101.5 & 97.1 & 97.1 \\
\hline Manufacturing milk price & 100.0 & 97.1 & 96.8 & 96.6 & 96.7 & 99.2 & 95.0 & 97.1 & 97.1 \\
\hline Blend price paid to dairy farms & 100.0 & 96.2 & 95.9 & 95.7 & 95.7 & 95.2 & 97.2 & 96.1 & 96.2 \\
\hline Generic milk advertising expenses & 100.0 & 101.7 & 98.8 & 96.0 & 102.0 & 101.2 & 102.3 & 79.6 & 124.3 \\
\hline
\end{tabular}

${ }^{1}$ Figures in parentheses are shares of the milk cow numbers to the total numbers.

${ }^{2}$ Average over all farms including rbST users and non-users. 
Table 6. Rates of return to rbST use in 2010.

\begin{tabular}{lllllllll}
\hline & \multicolumn{7}{c}{ Rate of return to rbST use $^{1}$} \\
\cline { 2 - 9 } group & Scenario 1 & Scenario 2 & Scenario 3 & Scenario 4 & Scenario 5 & Scenario 6 & Scenario 7 & Scenario 8 \\
\hline Small & 0.991 & 0.939 & 0.894 & 0.878 & 0.773 & 1.225 & 0.977 \\
Medium & 1.337 & 1.292 & 1.253 & 1.239 & 1.148 & 1.540 & 1.324 & 1.003 \\
Large & 1.577 & 1.538 & 1.503 & 1.491 & 1.411 & 1.756 & 1.566 & 1.586 \\
\hline
\end{tabular}

${ }^{1}$ Incremental per cow sales or a deviation from the sales in Scenario 0 divided by rbST-related per cow costs.

The effect of the milk advertising check-off program is evident in a comparison of scenarios 7 and 8 with scenario 1. If check-off rates are decreased as assumption (25; scenario 7), advertising expenses would shrink by about 1 billion yen, while total farm income would decline by 2.6 billion yen. This consequence implies that decreasing check-off money is short sighted as a means to mitigate farmers' income losses, since it would actually induce further income losses for farmers. On the other hand, scenario 8 indicates that if check-off rates are raised to the previous levels until 2000 as assumption (26), advertising expenses would increase by about 1 billion yen, while total farm income would increase by 2.1 billion yen. Hence, increasing check-off money could be one effective way to partially counter the negative effects of rbST approval on farm income.

To determine which rbST adoption rates are economically feasible, we examine the profitability of rbST use. Table 6 lists rates of return to rbST use in 2010. Rate of return is calculated as incremental per cow milk sales divided by rbST-related costs per cow, where incremental per cow milk sales is defined as a deviation from the sales in scenario 0 . The results indicate that the small herd-size group's rates of return are below one in all scenarios except scenario 6 . That is, rbST use is not economically feasible for this group because it is profitable only in the one scenario where the market was assumed to be less competitive (scenario 6). On the other hand, rbST is profitable enough for both the medium and large herd-size groups that rbST use could be adopted more widely than we assume in our scenarios.

As long as the rate of return exceeds one, economically rational farmers would increasingly use rbST. If the rbST adoption rate grows, milk price will decline because of the increase in milk supply, and the profitability of rbST use will thereby decline. We made trial calculations assuming such an interplay to assess to what extent rbST adoption rates could be higher for economic feasibility. Table 7 lists rates of return to rbST use that are calculated based on various assumed values for the medium and large herd-size groups' rbST adoption rates, and leaving the other assumptions at 2010 values in scenario 1 . The small herd-size group
rbST adoption rate is assumed to be zero, but its rate of return to rbST use is provisionally computed. When the medium and large herd-size group adoption rates are 15 and $55 \%$, respectively, the small herd-size group rate of return to rbST use is 1.136. That is, the small herd-size group could earn profits from rbST use if the other groups' adoption rates are lower than is assumed in the scenarios. If these rates grow to 25 and $65 \%$, the medium herd-size group falls below its break-even level. If the large herd-size group rbST adoption rate grows to 70\%, this group also falls below its break-even level. In this situation, the smaller herd-size group rate of return becomes even lower. This result implies that rbST use would become less profitable for smaller farms concurrent with wider adoption by the large farms. Therefore, income gaps among herd-size groups would widen.

The profitability of rbST is sensitive to assumed rates of milk yield increase with $\operatorname{rbST}$ use $\left(\operatorname{IR} Y_{i}\right)$, which is relatively uncertain. Therefore, the adequacy of the assumed values for this parameter should be examined. A rate of return to rbST use $(\pi)$ is defined as:

$$
\pi=\left[P Y_{i}\left(1+I R Y_{i}\right)-P_{0} Y_{i}\right] / I C_{i},
$$

where $P$ and $P_{0}$ are blend prices with and without rbST, respectively. To determine the rate of increase in milk yields due to rbST that would produce a break-even rate of return $(\pi=1.0)$, we use the 2010 value for $P_{0}$ in scenario 0 and the 2010 values for $P, Y_{i}$, and $I C_{i}$ in scenario 1 to solve for the values for $\operatorname{IRY} Y_{1}, I R Y_{2}$, and

Table 7. Decreases in rbST profitability due to increases in rbST adoption rates.

\begin{tabular}{|c|c|c|c|}
\hline \multirow{2}{*}{$\begin{array}{l}\text { Assumption of rbST adoption } \\
\text { rates for medium and large } \\
\text { herd-size group }\end{array}$} & \multicolumn{3}{|c|}{$\begin{array}{l}\text { Rate of return to rbST use } \\
\text { by herd-size group }\end{array}$} \\
\hline & Large & Medium & Small \\
\hline 10 and $50 \%$ & 1.159 & 1.495 & 1.726 \\
\hline 15 and $55 \%$ & 1.136 & 1.469 & 1.699 \\
\hline 20 and $60 \%$ & 0.930 & 1.284 & 1.531 \\
\hline 25 and $65 \%$ & 0.547 & 0.952 & 1.238 \\
\hline 30 and $70 \%$ & 0.151 & 0.609 & 0.936 \\
\hline
\end{tabular}

${ }^{1}$ The other assumptions are the same as 2010 values in Scenario 1. 
$I R Y_{3}$. The results indicate that rbST would have to increase milk yields in the three herd-size groups by $9.1,8.9$, and $8.9 \%$ (small, medium, and large, respectively) in order for them to achieve a break-even rate of return. That is, farmers adopting rbST would require milk yield increases of more than $9 \%$ in order to break even, a condition that is met for the medium and large herd-size groups given the assumption used in our simulations. This result also implies that if the small herdsize group could increase milk yield due to rbST by more than we assumed, it too could benefit from rbST usage.

\section{CONCLUSIONS}

A comprehensive econometric model was developed to evaluate the potential impacts of rbST approval on the Japanese dairy industry. Three novel features of the analysis were an investigation of herd-size structure, a determination of the economic feasibility of various rbST adoption rates, and an evaluation of policy alternatives for mitigating possible farm income losses due to rbST approval. Simulation analysis was conducted over a 10-yr period, assuming rbST approval in Japan in 2001.

The simulation results indicated that rbST approval would accelerate structural changes in Japan's dairy production toward fewer, larger farms. Approval of rbST was shown to harm smaller farms because they have a lower profit-earning ability because of higher costs, lower milk yields, and lower rates of rbST adoption. On the other hand, it was shown that larger farms could benefit from rbST adoption. However, if consumers' concerns about rbST-induced significant milk demand decreases, even larger farms' income and cow numbers would decrease. In this case, Japan's dairy industry would be caught in a double downward spiral of declining milk prices and production. Small farms could fare better if they used rbST if it is approved; they are best off if rbST is not approved at all.

To determine what rbST adoption rates are economically feasible, the profitability of rbST use was examined. In Japan, rbST use was found to be profitable enough for larger farms to be adopted more widely than we assumed in our scenarios. On the other hand, it was not profitable for smaller farms. Furthermore, it could become even less profitable for smaller farms as rbST use increases among larger farms.

The effects of market competitiveness and generic milk advertising funded from check-off programs were also examined. The results suggested 2 effective policies to mitigate the negative effects of rbST approval on farm income. First, farmers' income losses would be offset if dairy cooperatives could exercise more market power to control fluid milk marketing. Second, because generic milk advertising had positive effects on farm income as well as milk demand, increasing check-off rates could be one effective way to ease farmers' income losses due to rbST approval. Decreasing check-off rates was shown to be a shortsighted approach, since it would eventually induce further income losses for farmers.

\section{REFERENCES}

Barham, B. L. 1996. Adoption of a politicized technology: bST and Wisconsin dairy farmers. Am. J. Agric. Econ. 78:1056-1063.

Barham B. L., J. Foltz, S. Moon, and D. Jackson-Smith. 2004a. A comparative analysis of recombinant bovine somatotropin adoption across major U.S. Dairy regions. Rev. Agric. Econ. 26:32-44.

Barham, B. L., J. Foltz, D. Jackson-Smith, and S. Moon. 2004b. The dynamics of agricultural biotechnology adoption: Lessons from series rBST use in Wisconsin, 1994-2001. Am. J. Agric. Econ. 86:61-72.

Butler, L. J. 1999. The profitability of rbST on U.S. dairy farms. AgBioForum 2:111-117.

Cochrane, W. W. 1959. Farm Prices: Myth and Reality. University of Minnesota Press, Minneapolis.

Hartnell, G. F. 1995. Bovine somatotropin: production, management, and United States experience. Pages 189-203 in Animal Science Research and Development: Moving Toward a New Century. M. Ivan, ed. Center for Food and Animal Research, Agriculture and Agri-food, Ottawa, Canada.

Hosono, H. 1999. Measuring the effectiveness of milk promotion. Pages 263-265 in Collect. Pap. Jpn. Agric. Econ. Soc. Tokyo.

Jackson, L. A., and M. T. Villinski. 2002. Reaping what we sow: Emerging issues and policy implications of agricultural biotechnology. Rev. Agric. Econ. 24:3-14.

Kaiser, H. M. 2000. Impact of generic fluid milk and cheese advertising on dairy markets 1984-1999. NICPRE00-01, R.B. 2000-02, Dep. Agric. Res. Manag. Econ., Cornell Univ., Ithaca, NY.

Kaiser, H. M., C. W. Scherer, and D. M. Barbano. 1992. Consumer perceptions and attitudes towards bovine somatotropin. Agric. Res. Econ. Rev. 21:10-20.

Kaiser, H. M., and L. W. Tauer. 1989. Impact of bovine somatotropin on U.S dairy markets under alternative policy options. N. Central J. Agric. Econ. 11:59-73.

Karszes, J., W. A. Knoblauch, and L. D. Putnam. 2001. Business summary, New York large head farms, 300 cows or larger, 2000. R.B. 2001-06, Dep. Agric. Res. Manag. Econ., Cornell Univ., Ithaca, NY

Kinoshita, J., N. Suzuki, and H. M. Kaiser. 2002. Explaining pricing conduct in a product-differentiated oligopolistic market: An empirical application of a price conjectural variation model. Agribusiness 18:427-436.

Knoblauch, W. A., and L. D. Putnam. 1997. Business summary, New York State, 1996. R.B. 97-14, Dep. Agric. Res. Manag. Econ., Cornell Univ., Ithaca, NY.

Knoblauch, W. A., L. D. Putnam, and J. Karszes. 1999. Business summary, New York State, 1998. R.B. 99-11, Dep. Agric. Res. Manag. Econ., Cornell Univ., Ithaca, NY.

Knoblauch, W. A., L. D. Putnam, and J. Karszes. 2001. Business summary, New York State, 2000. R.B. 2001-06, Dep. Agric. Res. Manag. Econ., Cornell Univ., Ithaca, NY.

Kuperis, P. A., M. M. Veeman, and W. L. Adamowicz. 1999. Consumer's responses to the potential use of bovine somatotropin in Canadian dairy production. Can. J. Agric. Econ. 47:151-163.

Marion, B. W., and R. L. Wills. 1990. A prospective assessment of the impacts of bovine somatotropin: a case study of Wisconsin. Am. J. Agric. Econ. 72:326-336.

McBride, W. D., S. Short, and H. El-Osta. 2004. The adoption and impact of bovine somatotropin on U.S. dairy farms. Rev. Agric. Econ. (accepted)

Monsanto Corporation. 2002. Subject: POSILAC 1 STEP General Information Update. Online. Available: http://www.monsanto dairy.com/updates/Bovine.html. Accessed Dec. 20, 2002. 
Office of Management and Budget. 1994. Use of bovine somatotropin (BST) in the United States: its potential effects: U.S. OMB report, Washington, DC.

Smith, S. F., W. A. Knoblauch, and L. D. Putnam. 1995. Business summary, New York State, 1994. R.B. 95-03, Dep. Agric. Res. Manag. Econ., Cornell Univ., Ithaca, NY.

Stefanides, Z., and L. W. Tauer. 1999. The empirical impact of bovine somatotropin on a group of New York dairy farms. Am. J. Agric. Econ. 81:95-102.

Suzuki, N. 1995. Effects of bST on the U.S. Dairy Sector. Nosoken Kiho, Policy Res. Inst., Japanese Ministry Agric. 28:1-20.
Suzuki, N., and H. M. Kaiser. 1997. Imperfect competition models and commodity promotion evaluation: The case of U.S. generic milk advertising. J. Agric. Appl. Econ. 29:315-325.

Suzuki, N., H. M. Kaiser, J. E. Lenz, K. Kobayashi, and O. D. Forker. 1994. Evaluating generic milk promotion effectiveness with an imperfect competition model. Am. J. Agric. Econ. 76:296-302.

Suzuki, N., J. E. Lenz, and O. D. Forker. 1993. A conjectural variations model of reduced Japanese milk price supports. Am. J. Agric. Econ. 75:210-218.

Tauer, L. W. 1994. The value of segmenting the milk market into bST-produced and non-bST-produced milk. Agribusiness 10:3-12. 